\title{
Monitoring temporal fluctuations of Culex quinquefasciatus using oviposition traps containing attractant and larvicide in an urban environment in Recife, Brazil
}

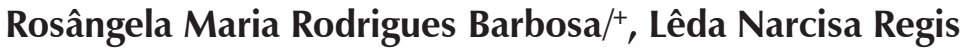 \\ Departamento de Entomologia, Centro de Pesquisas Aggeu Magalhães-Fiocruz, \\ Av. Prof. Moraes Rego s/n, 50670-420 Recife, PE, Brasil
}

The use of attractants and larvicides in oviposition traps is of practical interest for the surveillance and control of urban mosquitoes. In addition to increasing the safety of the traps, this combination is essential for an attract-and-kill control strategy based on trapping mosquito eggs. The combination of Bacillus thuringiensis var. israelensis (Bti) and grass infusion (GI) vs. GI alone were tested for their ability to attract in paired BR-OVT traps in the backyards of 10 houses in Recife, Brazil, for a period of 45 days. Results show that females prefer to oviposit in traps containing Bti (363 compared with 251 egg rafts over 45 days). Results from a one-year trial on the efficacy of BR-OVT traps loaded with GI and Bti as a sampling tool to monitor temporal fluctuations in the population densities of Culex quinquefasciatus in an urban environment are also reported. From December 2006-January 2007, one trap per home was installed and maintained for 348 consecutive days in 134-151 houses located in three urban blocks. Throughout the one-year field trial a total of 43,151 Culex egg rafts were collected in the traps. The data show that BR-OVT loaded with GI and Bti is sensitive enough to demonstrate continuous reproductive activity of $\mathrm{Cux}$. quinquefasciatus in the study area throughout the year and to monitor temporal fluctuations in population density.

Key words: Culicidae - ovitrap - BR-OVT - Bacillus thuringiensis israelensis - oviposition attractant

Culex quinquefasciatus Say is a common urban mosquito with highly endophilic and anthropophilic behaviour. Its breeding sites are mostly located inside or near houses. Thus, it benefits from anthropogenic changes in the peridomiciliary environment. In tropical areas where environmental factors favour an abundance of breeding sites and rapid biological development, very high population densities of Cux. quinquefasciatus can be maintained for long periods, causing great annoyance and a strong risk of pathogen transmission to people. In Recife, state of Pernambuco, Brazil, climatic factors and inadequate sanitation contribute to high mosquito production year round, mainly in cesspits and drains (Regis et al. 1995, 2000). Cux. quinquefasciatus, the vector of Wuchereria bancrof$t i$ in the Americas, is responsible for keeping the metropolitan region of Recife endemic for lymphatic filariasis (Maciel et al. 1996, Medeiros et al. 1999, MS 2000, WHO 2007). Due to the rapid growth of urban areas in tropical zones and the involvement of Cux. quinquefasciatus in the transmission of arboviruses such as West Nile Virus (Nasci et al. 2001, Zinser et al. 2004), this mosquito has become a matter of growing concern in recent years.

Different trap models have been employed as tools for estimating the population densities of Culex mosqui-

+ Corresponding author: barbosar@cpqam.fiocruz.br

Received 6 December 2010

Accepted 25 March 2011 toes and for monitoring the impact of control actions on the insect population (Ritchie 1984, Mboera et al. 2000). Most available traps are designed to catch $\mathrm{Cux}$. quinquefasciatus adults and require the use of electric energy for fans and/or lights, which limits their use in low-income areas, especially when considering long-term programs. Oviposition traps are generally much simpler devices, as they do not require electricity (Barbosa et al. 2007). These traps may become a valuable instrument for sampling Culex mosquitoes in the production of entomological data and may potentially be used to remove massive numbers of eggs from the environment in vector-integrated management programs.

The use of oviposition attractants and larvicides in traps has important practical interest for the surveillance and control of urban mosquitoes. In addition to increasing the safety of the traps by not allowing them to become breeding sites, this combination is essential for an attract-and-kill control strategy based on trapping mosquito eggs. It is well known that volatile products of microbial activity attract gravid female mosquitoes for oviposition (Millar et al. 1992, Isoe et al. 1995, Ponnusamy et al. 2010). In recent years, there has been growing lab and field evidence indicating that the entomopathogenic bacteria Bacillus thuringiensis var. israelensis (Bti) and Bacillus sphaericus may function as attractants for $\mathrm{Ae}$ des and Cux. quinquefasciatus mosquitoes (Poonam et al. 2002, Santos et al. 2003, Stoops 2005, Barbosa et al. 2007, 2010, Carrieri et al. 2009).

The BR-OVT, a very simple oviposition trap, was developed by assimilating components to attract gravid Culex females for oviposition (Barbosa et al. 2007). 
Field trials in Recife have shown that BR-OVT loaded with a grass infusion (GI) with or without $B$. sphaericus as a larvicide, works as a preferred oviposition site for Cux. quinquefasciatus (Barbosa et al. 2007). Moreover, recent tests have demonstrated that skatole or GI can be used to enhance the number of egg rafts deposited on Bti-treated BR-OVT (Barbosa et al. 2010).

We report here the results of an extensive field trial on the sensitivity and efficacy of BR-OVT loaded with GI and Bti as a sampling tool to monitor temporal fluctuations in the population densities of Cux. quinquefasciatus in an urban environment.

\section{MATERIALS AND METHODS}

In this study, the BR-OVT trap was evaluated for its efficiency in the continuous collection of Culex eggs in an urban area that is a high-risk region for filariasis transmission. This field trial was preceded by laboratory tests (Barbosa et al. 2007) on the use of Bti in the trap. The BR-OVT is composed of a simple black plastic box with a central window on the top surface and a black bowl filled with water, oviposition attractant and microbial larvicide (Barbosa et al. 2007).

The study area - Recife ( $8^{\circ} 03^{\prime}$ 'S $34^{\circ} 52^{\prime} \mathrm{W}$ ), with 1.5 million inhabitants, is located in the Northeast Region of Brazil. Throughout the year, temperatures range from $22-32^{\circ} \mathrm{C}$ and the relative air humidity oscillates from 70 $90 \%$. Rainfall can be heavy and prolonged in the wet season from April-July, but is sparse in the dry season.

Influence of Bti on the choice of oviposition site - A pair of BR-OVT was deployed in each of 10 houses located in Mustardinha, a neighbourhood of Recife. Each pair was formed by one trap loaded with GI plus Bti and one trap containing GI alone. The product based on Bti (Vectobac CG, Valent Biosciences, Libertyville, IL) was used at $0.45 \mathrm{mg} / \mathrm{L}$, a dose corresponding to $30 \times \mathrm{LC} 50$ $(0.015 \mathrm{mg} / \mathrm{L})$ for the Cux. quinquefasciatus Recife strain (Pei et al. 2002). GI was prepared by adding $150 \mathrm{~g}$ of fresh Eleusine indica (Poaceae) to $10 \mathrm{~L}$ of tap water in a storage bottle and letting the mixture settle for seven days at room temperature. The paired traps were installed at least $1.5 \mathrm{~m}$ apart from each other and remained for a period of 45 days (December 2006-January 2007) in the backyard of each home. Every two days, egg rafts found in each trap were removed, counted and safely discarded. The GI (undiluted) was replaced in the traps every 15 days and $B t i$ was reapplied fortnightly.

Mosquito population surveillance - The experiment was carried out in Mustardinha, using BR-OVT traps loaded with $800 \mathrm{~mL}$ of undiluted GI and Bti $(0.45 \mathrm{mg} / \mathrm{L})$. Traps were installed with the agreement of householders, preferentially indoors or, alternatively, in the backyards. In at least 107 houses located within three contiguous blocks, one trap remained installed for 348 consecutive days, from 19 January-31 December 2006. The initial number of traps was reduced throughout the first month due to refusal or withdrawal of participants, changes of address or difficulty in accessing the house. Extra ovitraps were installed during the experiment, in response to household requests. Thus, from February-November
2006, a minimum of 134 and a maximum of 151 ovitraps were continuously present in the study area. The percentage of traps located indoors fluctuated from 67$70 \%$ over the study period. Only three traps were lost over the one-year experiment. Because of large differences in the number of traps used in the first (181) and last month (107), data from January and December were excluded from the analysis. Traps were inspected every three days, when laid egg rafts were removed, counted and safely discarded. The egg rafts found in the traps were assumed to be from Cux. quinquefasciatus, based on previous studies carried out by our team in the urban areas of Recife and Olinda, in which Cux. quinquefasciatus was the only mosquito species found in CDC light traps (Regis et al. 1995, 2000). This observation was more recently confirmed through polymerase chain reaction assays analysing adult mosquito samples caught in gravid traps (Leal et al. 2008).

Entomological data on Cux. quinquefasciatus, obtained from the Program for Lymphatic Filariasis Elimination (City Hall of Recife), was used as a reference for the presence or absence of this mosquito in the study area. These data are based on mosquito sampling using miniature CDC light traps equipped with incandescent light, installed in collection stations for one week every month. Only four light traps from the official Filariasis Program were located within (2) or near (2) our study area. The rainfall data were obtained from the SAUDAVEL Database/Recife.

Data analysis - The total numbers of egg rafts per trap were compared between treatments and control using the Wilcoxon signed-rank test (Siegel \& Castellan 1988). Values of $\mathrm{p} \leq 0.05$ (2-tailed) were considered significant. The oviposition activity index (OAI) was estimated according to Kramer and Mulla (1979) as follows:

$$
\mathrm{OAI}=\mathrm{N}_{\mathrm{T}}-\mathrm{N}_{\mathrm{S}} / \mathrm{N}_{\mathrm{T}}+\mathrm{N}_{\mathrm{S}}
$$

where $\mathrm{N}_{T}$ is the number of ovipositions (egg rafts, in the case of Culex) in the treatment and $\mathrm{N}_{\mathrm{S}}$ is the number of egg rafts in the control. Index values lay within the range of +1 to -1 and values greater than zero indicate that females did not avoid ovipositing in containers with Bti (Allan \& Kline 1995).

To assess seasonal variations in mosquito abundance, the percent of positive traps for eggs and the frequency of traps according to the number of egg rafts per month were calculated, using classes of the same size (1-20, 21$40,41-60$ and $>60 \mathrm{rafts} / \mathrm{month})$. For population density, the average number of egg rafts per house per day was estimated monthly, excluding the months with the highest and the lowest numbers of installed traps, respectively, January (181) and December (129-107), to avoid the eventual effects of high variations in trap numbers on the estimated densities.

\section{RESULTS}

The influence of Bti in the choice of oviposition sites From a total of 614 egg rafts counted in 20 ovitraps ( 2 per house) over 45 days, 363 (59.1\%) were laid in the BR-OVT containing GI $+B t i$, which is significantly higher $(\mathrm{p}<$ 0.05 ) than the total number of egg rafts laid in the respec- 
tive pairs containing GI alone. The OAI for the presence of $B t i$ was +0.18 . As shown in Fig. 1, in eight out of 10 houses the number of egg rafts laid was clearly higher in the BROVT loaded with $B t i+$ GI than in the respective control pairs; in one out of 10 houses the number of rafts laid in the paired traps was similar: 51 and 53 (house 6) (Fig. 1).

Mosquito population surveillance - Culex egg rafts were collected from the BR-OVTs throughout the year. A total of 43,151 egg rafts were collected from JanuaryDecember. In February, $62.7 \%$ of traps were positive for eggs; however, most of them contained less than 20 egg rafts (Table). From March onward, the percentage of positive traps each month was higher than $90 \%$, reaching the highest values in August (98.7\%) and December (99.1\%). Over this period, the majority (60-80\%) of traps contained one-40 egg rafts every month, but an increasing number of traps contained more than 40 egg rafts per month, especially from August-October (26.7-34.3\% of the traps). In

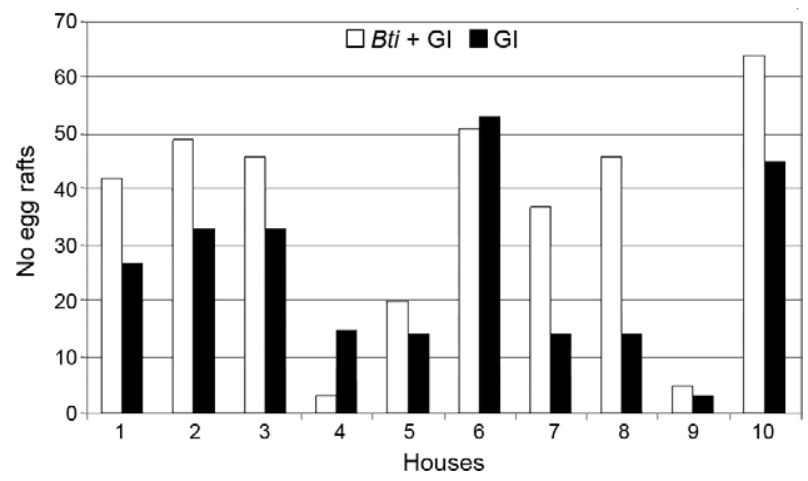

Fig. 1: number of egg rafts laid by Culex quinquefasciatus females during 45 days in BR-OVT ovitraps loaded with grass infusion (GI) with or without Bacillus thuringiensis var. israelensis (Bti) in Mustardinha, Recife, Brazil, 2006.

TABLE

Percentages of ovitraps according to the amount of egg rafts collected per trap per month from January-December 2006, in Recife, Brazil

\begin{tabular}{lccccc}
\hline & \multicolumn{5}{c}{ BR-OVT according to egg raft numbers } \\
& $\begin{array}{c}\text { Negative } \\
\text { BR-OVT }\end{array}$ & \multicolumn{5}{c}{ \% } \\
\cline { 3 - 6 } Month & $\%$ & $1-20$ & $21-40$ & $41-60$ & $>61$ \\
\hline Feb & 37.3 & 53.7 & 5.9 & 2.3 & 0.7 \\
Mar & 7.7 & 58.9 & 22.4 & 6.2 & 4.7 \\
Apr & 3.5 & 56.4 & 24.4 & 10.7 & 5 \\
May & 2.8 & 39.8 & 29.8 & 15.6 & 12 \\
Jun & 3.6 & 54 & 23.7 & 5.7 & 12.9 \\
Jul & 3.4 & 44.8 & 29.6 & 8.9 & 13.1 \\
Aug & 1.3 & 35.2 & 29.7 & 16.6 & 17.2 \\
Sep & 3.4 & 45.2 & 24.6 & 9 & 17.8 \\
Oct & 6.3 & 31.7 & 27.6 & 13.7 & 20.7 \\
Nov & 5.5 & 46 & 25.8 & 7.8 & 14.9 \\
\hline
\end{tabular}

October, $20.6 \%$ of the traps contained more than 60 egg rafts, i.e., two or more rafts per day, on average.

The population density, as indicated by the average number of egg rafts per house per day, showed a relevant increase from February-March and increasing densities were recorded until October with a slight decrease in September (Fig. 2). From July-October, roughly one egg raft per house was collected every day. Over the entire period, significantly $(p=0.049)$ more egg rafts were laid in the traps located outdoors vs. indoors (Fig. 2). A progressive population growth occurred during and soon after the rainy season, with the highest mosquito densities being recorded in August-October, the beginning of the dry season. This population growth was more easily detected in traps located outdoors (Fig. 2).

Data from the City Hall of Recife on the numbers of Cux. quinquefasciatus sampled using four CDC light traps in Mustardinha in 2006 also indicated the presence of this mosquito every month throughout the year. A range of $<$ 1-28 mosquitoes per house per night was observed, with increased densities from July-December, i.e., at the end of the rainy season and after the rainy season (Fig. 3).

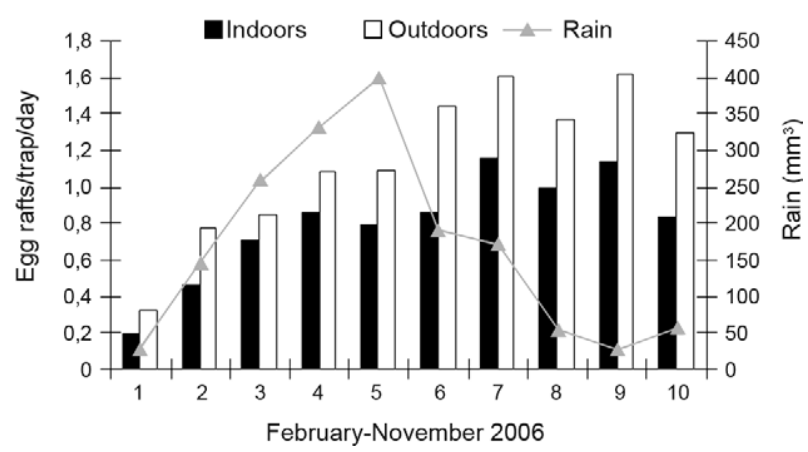

Fig. 2: mean number of egg rafts laid by Culex quinquefasciatus females in BR-OVT ovitraps indoors and outdoors from February-November and monthly rainfall levels in Mustardinha, Recife, Brazil, 2006.

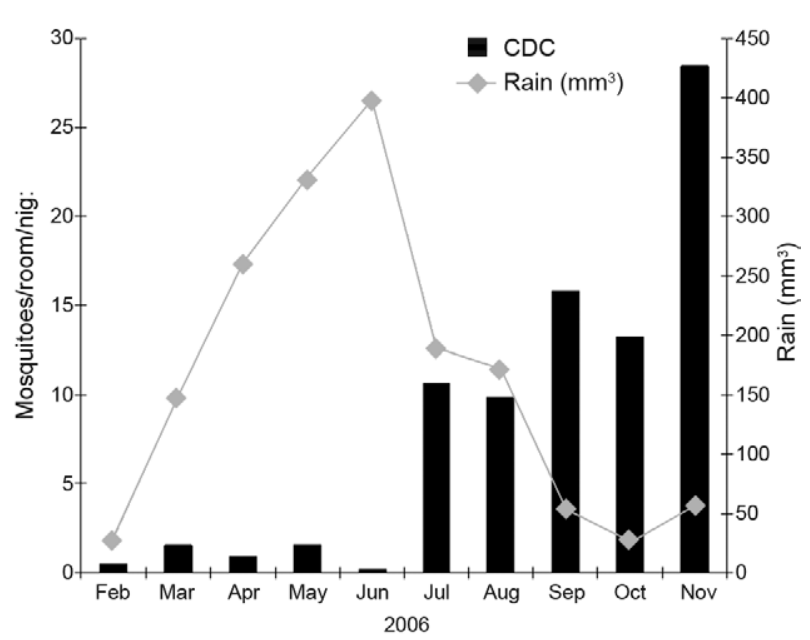

Fig. 3: mean number of Culex quinquefasciatus females per room per night, based on adult mosquito capture with CDC light traps, and rainfall levels in Mustardinha, Recife, Brazil, 2006. 


\section{DISCUSSION}

In these field experiments, carried out in a neighbourhood of Recife, Brazil, the trapping effects of a combination Bti-GI vs. GI alone in luring female mosquitoes into ovitraps was evaluated using paired BR-OVT traps in the backyards of houses. The data showed an OAI $>0$ and a significant difference between the treatment and the control, indicating a preference of females to oviposit in those traps containing Bti. A previous series of oviposition assays in a choice chamber served as a basis for these field experiments, as the previously collected data clearly indicated that Bti applied to water enhanced the egg-laying of Cux. quinquefasciatus when compared to untreated water (Barbosa et al. 2007). Our present observations, perhaps the first obtained in a field test on the suitability of Bti for Cux. quinquefasciatus oviposition, may have practical implications for mosquito control program; the preference of Culex females to oviposit in traps containing Bti may reduce mosquito proliferation in other potential breeding places that co-exist in the same house, but do not contain this bacterial larvicide. This reinforces the use of $B t i$ as an efficient larvicide against urban mosquito species from the Culex and Aedes genera. In addition to the long persistence of Bti larvicidal activity in shaded areas (Melo-Santos et al. 2009), and the fact that no mosquito resistance has been recorded after decades of Bti use (Becker 1997, Regis et al. 2001), this larvicide can help attract gravid females (Santos et al. 2003, Stoops 2005, Carrieri et al. 2009, Barbosa et al. 2010), potentially promoting the concentration of mosquito eggs in lethal ovitraps. Due to the safety guaranteed by the persistent larvicidal action of $B t i$, frequent inspections of the traps, as performed throughout this study, is unnecessary. In surveillance programs using the BR-OVT, Bti can be reapplied monthly, as for ovitraps used for sampling Aedes aegypti eggs (Regis et al. 2008).

Throughout the one-year field study, more than 43,000 Culex egg rafts were laid in BR-OVT traps baited with the GI plus Bti. Based on results that reveal a better performance of BR-OVTs inside the houses (Barbosa et al. 2007), a preference was given to the intradomiciliary installation of traps. Acceptance by the households was satisfactory and most traps were placed inside houses. Some houses withdrew within the first month of the study; nevertheless, it was possible to maintain, from February-November, 135-151 traps that were visited twice a week, indicating receptivity by the households. In contrast to the results observed in Caçote, another neighbourhood of Recife (Barbosa et al. 2007), in the present survey, consistently more egg rafts were laid in the BR-OVT located in the backyard rather than traps located inside houses. Differences in the localisation and primary types of Culex breeding places between those urban areas of Recife are a possible explanation for the different proportions of egg rafts collected indoors and outdoors. The data appear to suggest that the dark and wind-protected microenvironment created by the black box of the BR-OVT guarantees its efficacy in attracting gravid females, irrespective of its location (indoors or outdoors).
The results reveal that the BR-OVT tool is sensitive enough to record continuous reproductive activity of $\mathrm{Cux}$. quinquefasciatus throughout the year in Mustardinha, as well as to indicate temporal fluctuations in mosquito densities. It was clearly shown that the Culex population increases in parallel with an increase in rainfall, progressively growing during the rainy season and reaching higher densities in the following months, indicating the occurrence of large, persistent bodies of water. In addition to creating new breeding places, heavy rainfall will enlarge the surface area of existing bodies of water, such as wastewater pools, and as a consequence increasing the available area for mosquito production. The increased population densities observed after the rainy season suggest the existence of environmental conditions favouring the accumulation and persistence of rain water in exposed places. During the period of highest reproductive activity within the mosquito population, the profile of eggraft sampling suggested a daily presence of at least one gravid female in every monitored house.

The data from the Recife Health Service on adult mosquito sampling using light traps also indicated the occurrence of Cux. quinquefasciatus every month throughout the year in that neighbourhood in Mustardinha, showing a similar temporal distribution. It is important to mention that densities measured by these different trapping methods may not be comparable because light traps attract and catch young, unfed, recently bloodfed and resting mosquitoes as well as gravid females, while an egg raft deposited in an ovitrap selectively represents the visit of one gravid female. Furthermore, the small number of adult traps (n $=4$ ) does not allow any statistical comparison with data from the oviposition traps $(n=134$ or $n=151)$. Nevertheless, data gathered by both methods show a higher abundance of Culex in the second semester of the year. They also indicate that mosquito abundance may be considered low to moderate, as compared to entomological data gathered in that area in previous years, when adult trapping from 1991-1994 showed monthly oscillations ranging from 20-60 mosquitoes per room per night throughout the year, with a peak of 95-100 mosquitoes per room per night at the apex of the rainy season in June-July (Regis et al. 1995). The current data possibly reflect the effects of environmental management strategies implemented after the earlier mosquito survey (1991-1994), including street paving and improvements to the water drainage system, possibly eliminating open drains, then considered the main Culex breeding site in Mustardinha (Regis et al. 1995). Environmental changes modifying characteristics related to rain water retention may account for the shift in the peak mosquito density in Mustardinha from JuneJuly (in 1991-1994) to August-October (in 2006). Culex surveys carried out in the Metropolitan Region of Recife from 1991-1994 have shown a marked annual peak of mosquito density in June-July in Coque, another neighbourhood of Recife (Regis et al. 1995), while in Jardim Brasil, a neighbourhood of Olinda, the peak has been recorded in January-February (Regis et al. 2000), demonstrating different temporal distributions for mosquito densities in two urban areas under the same rainfall regime. 
The amount of eggs removed from the environment suggests the existence of highly productive sources of mosquitoes, enough to continuously maintain a well established Culex population in that area: 43,151 egg rafts comprises possibly more than six million eggs, or approximately 18,000 eggs per day, over one year.

The present results clearly demonstrate the sensitivity of the BR-OVT as a survey tool and point out its significant potential for egg collection, which could help reduce local Culex populations if integrated into existing environmental management measures. The possibility of employing more practical oviposition attractants than a grass infusion, as shown recently by Barbosa et al. (2010), and the low cost of the BR-OVT trap, which does not require a source of electricity, may facilitate the set up of two or more traps per house, indoors and outdoors, in an attempt to enhance the efficacy of the attract-and-kill control strategy. Due to its practical characteristics, the BR-OVT can be used as a monitoring tool for Culex in a spatial surveillance system similar to the Monitoring System and Population Control of Aedes (Regis et al. 2009).

\section{REFERENCES}

Allan SA, Kline DL 1995. Evaluation of organic infusions and synthetic compounds mediating oviposition in Aedes albopictus and Aedes aegypti (Diptera: Culicidae). J Chem Ecol 21: 1847-1860.

Barbosa RMR, Regis L, Vasconcelos R, Leal WS 2010. Culex mosquitoes (Diptera: Culicidae) egg laying in traps loaded with $\mathrm{Ba}$ cillus thuringiensis variety israelensis and baited with skatole. J Med Entomol 47: 345-348.

Barbosa RMR, Souto A, Eiras EA, Regis L 2007. Laboratory and field evalution of an oviposition trap for Culex quinquefasciatus (Diptera: Culicidae). Mem Inst Oswaldo Cruz 102: 523-529.

Becker N 1997. Microbial control of mosquitoes: management of the Upper Rhine mosquito population as a model programme. Parasitol Today 13: 485-487.

Carrieri M, Masetti A, Albieri A, Maccagnani B, Bellini R 2009. Larvicidal activity and influence of Bacillus thuringiensis var. israelensis on Aedes albopictus oviposition in ovitraps during a twoweek check interval protocol. J Am Mosq Cont Assoc 25: 149-155.

Isoe J, Millar JG, Beehler JW 1995. Bioassays for Culex (Diptera: Culicidae) mosquito oviposition attractants and stimulants. J Med Entomol 32: 475-483.

Kramer NL, Mulla MS 1979. Oviposition attractants and repellents of mosquitoes: oviposition response of Culex mosquitoes to organic infusion. Environ Entomol 8: 1111-1117.

Leal WS, Barbosa RMR, Xu W, Ishida Y, Syed Z, Latte N, Chen AM, Morgan TI, Cornel AJ, Furtado A 2008. Reverse and conventional chemical ecology approaches for the development of oviposition attractants for Culex mosquitoes. PLoS ONE 3: e3045.

Maciel A, Rocha A, Marzochi KBF, Medeiros Z, Carvalho ABC, Regis L, Souza W, Lapa T, Furtado A 1996. Epidemiological study of bancroftian filariasis in Recife, Northeastern Brazil. Mem Inst Oswaldo Cruz 91: 449-455.

Medeiros Z, Gomes J, Beliz F, Coutinho A, Dreyer P, Dreyer G 1999. Screening of army soldiers for Wuchereria bancrofti infection in metropolitan Recife region, Brazil: implications for epidemiologic surveillance. Trop Med Intern Health 4: 499-505.

Melo-Santos MAV, Araújo AP, Rios EMM, Regis L 2009. Long lasting persistence of Bacillus thuringiensis var. israelensis larvicidal activity in Aedes aegypti (Diptera: Culicidae) breeding places is associated to bacteria recycling. Biological Control 49: 186-191.
Millar JG, Chaney JD, Mulla MS 1992. Identification of oviposition attractants for Culex quinquefasciatus from fermented Bermuda grass infusions. J Am Mosq Cont Assoc 8: 11-17.

MS - Ministério da Saúde 2000. Relatório da Reunião de Avaliação do Programa de Controle da Filariose Linfática no Brasil, Centro Nacional de Epidemiologia/MS, Brasília. Available from: portalsaude.gov.br/Relatorio_SIS.

Mboera LEG, Takken W, Mdira KY, Peakett JA 2000. Sampling gravid Culex quinquefasciatus (Diptera: Culicidae) in Tanzania with traps baited with synthetic oviposition pheromone and grass infusion. J Med Entomol 37: 172-176.

Nasci RS, Savage HM, White DJ, Miller JR, Cropp BC, Godsey MS, Kerst AJ, Bennett P, Gottfried K, Lanciotti RS 2001. West Nile virus in overwintering Culex mosquitoes, New York City, 2000. Emerg Infect Dis 7: 742-744.

Pei G, Oliveira CMF, Yuan Z, Nielsen-LeRoux C, Silva-Filha MH, Yan J, Regis L 2002. Astrain of Bacillus sphaericus causes a slower development of resistance in Culex quinquefasciatus. Appl Environ Microbiol 68: 3003-3009.

Ponnusamy L, Xu N, Böröczky K, Wesson DM, Ayyash LA, Schal C, Apperson C 2010. Oviposition responses of the mosquitoes Aedes aegypti and Aedes albopictus to experimental plant infusions in laboratory bioassays. J Chem Ecol 36: 709-719.

Poonam S, Paily KP, Balaraman K 2002. Oviposition attractancy of bacterial culture filtrates - Response of Culex quinquefasciatus. Mem Inst Oswaldo Cruz 97: 359-362.

Regis L, Monteiro AM, Melo-Santos MAV, Silveira JC Jr, Furtado AF, Acioli RV, Santos GM, Nakazawa M, Carvalho MS, Ribeiro PJ Jr, Souza WV 2008. Developing new approaches for detecting and preventing Aedes aegypti population outbreaks: basis for surveillance, alert and control system. Mem Inst Oswaldo Cruz 103: 50-59.

Regis L, Oliveira CMF, Silva-Filha MH, Silva SB, Maciel A, Furtado AF 2000. Efficacy of Bacillus sphaericus in control of the filariasis vector Culex quinquefasciatus in an urban area of Olinda, Brazil. Trans R Soc Trop Med Hyg 94: 488-492.

Regis L, Oliveira CMF, Silva-Filha MH, Silva SB, Maciel A, Furtado AF 2001. Bacteriological larvicides of diptera disease vectors. Trends Parasitol 17: 377-380.

Regis L, Silva-Filha MH, Oliveira CMF, Rios EM, Silva SB, Furtado AF 1995. Integrated control measures against Culex quinquefasciatus, the vector of filariasis in Recife. Mem Inst Oswaldo Cruz 90: 115-119.

Regis L, Souza WV, Furtado AF, Fonseca CD, Silveira JC Jr, Ribeiro PJ Jr, Melo-Santos MAV, Carvalho MS, Monteiro AM 2009. An entomological surveillance system based on open spatial information for participative dengue control. An Acad Bras Cienc 81: 1-8.

Ritchie SA 1984. Hay infusion and isopropyl alcohol-baited CDC light trap; a simple, effective trap for gravid Culex mosquitoes. Mosquito News 44: 404-407.

Santos SRA, Melo-Santos MAV, Regis L, Albuquerque CMR 2003. Field evaluation of ovitraps consociated with grass infusion and Bacillus thuringiensis var. israelensis to determine oviposition rates. Dengue Bulletin 27: 156-162.

Siegel S, Castellan NJ 1988. Nonparametric statistics for the behavioral sciences, 2nd ed., McGraw-Hill, New York, 399 pp.

Stoops CA 2005. Influence of Bacillus thuringiensis var. israelensis on oviposition of Aedes albopictus (Skuse). J Med Entomol 30: 41-44.

WHO - World Health Organization 2007. Global Programme to Eliminate Lymphatic Filariasis. Wkly Epidemiol Rec 42: 361-380.

Zinser M, Ramberg F, Willott E 2004. Culex quinquefasciatus (Diptera: Culicidae) as a potential West Nile virus vector in Tucson, Arizona: blood meal analysis indicates feeding on both humans and birds. J Insect Sci. Available from: www.insectscience.org/4.20. 